\title{
Natural History Collections: A Scientific Treasure Trove
}

Natural history collections play an indispensable and often overlooked role in the conservation and management of our Nation's flora and fauna. Scientific specimens housed in museum collections not only open an important window into the current and past diversity of life on Earth, but also play a vital role in fueling cutting-edge scientific research in many disciplines. The U.S. Geological Survey (USGS) Fort Collins Science Center (FORT) curates a collection of vertebrates from the Intermountain and Southwestern United States that is used by researchers from around the globe. As one of the largest Federal natural history collections in the western United States, the USGS specimen holdings offer unique opportunities to study the fauna of this incredibly diverse and unique region.

\section{Characterizing Diversity}

Nearly all of our organized knowledge of the distributions, diversity, and relationships of living organisms is the result of studying museum specimens. Our whole system of scientific nomenclature is based on examination of representative plants and animals in museums. In fact, individual species' names are tied directly to holotype specimens (the original animals used to define each species) housed in museums, and nearly every known species of plant and animal is represented by one or more specimens in scientific museum collections. In addition to the role of specimens in supporting the concept of "species" as we currently understand it, the descriptions, illustrations, and range maps we commonly see in field guides that are used by millions of wildlife enthusiasts would not be possible without such collections. Anyone who has tried to describe a plant or animal from a fleeting observation can appreciate the great utility of today's field guides that are grounded by study of scientific specimens.

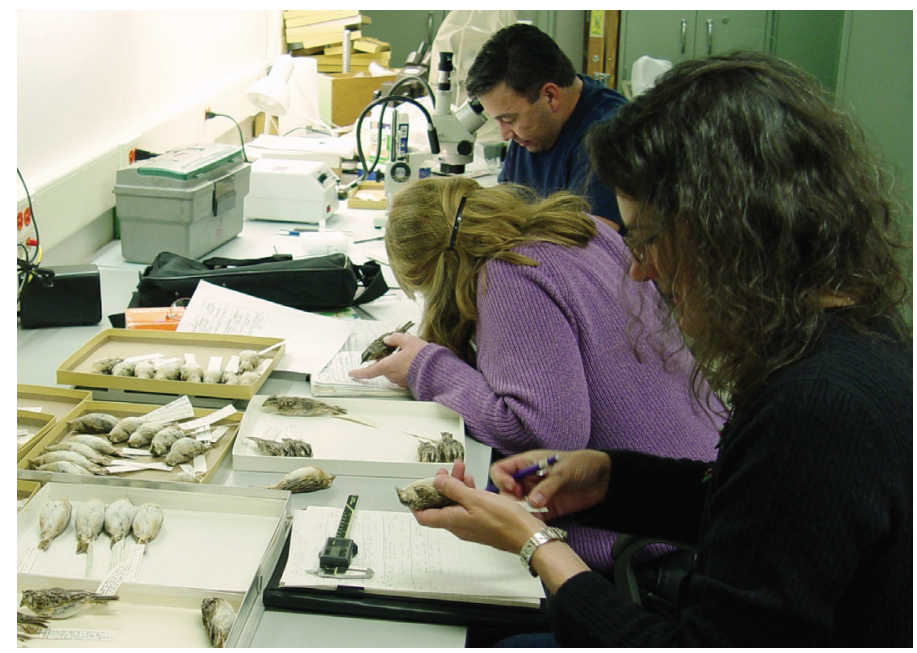

Federal scientists record body measurements and assess color variation in Grasshopper Sparrows. USGS photo.

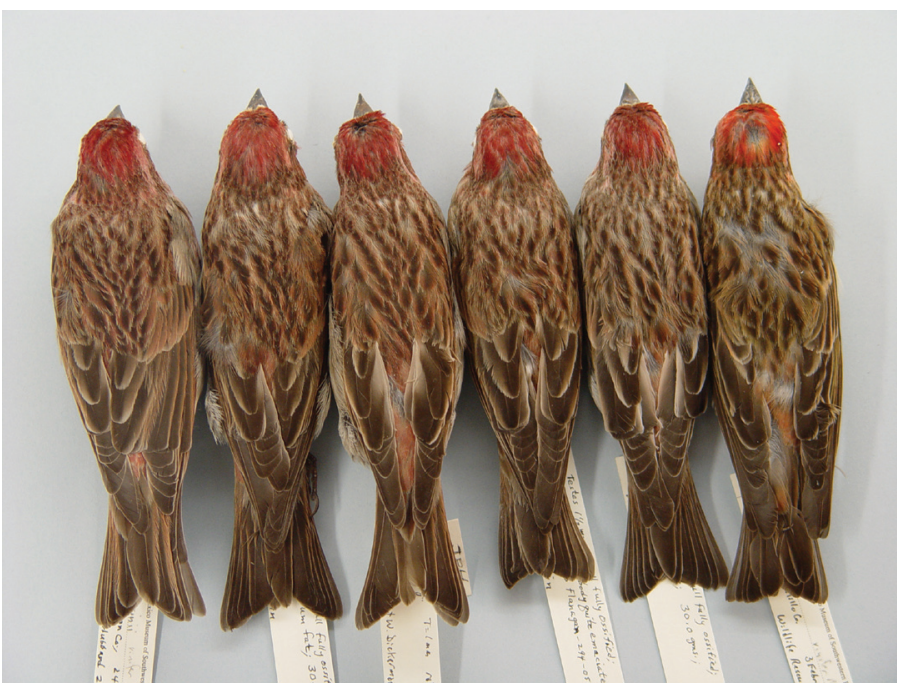

Series of Cassin's Finches showing regional morphological variations. Photo by Jane Mygatt, University of New Mexico.

\section{Verifying Taxonomy}

Scientists historically studied the morphological characteristics (for example, shape, size, and color) of museum specimens to define and differentiate plant and animal species. In recent decades, taxonomic studies have expanded upon the analysis of visible traits and now incorporate genetic information, a technique that relies heavily on tissue samples housed in museums. Taxonomists are continually revising and refining our understanding of the relationships among plants and animals at several different levels, ranging from subspecies to family. Revisiting such taxonomic relationships is imperative not only to our proper understanding of the natural world, but also for making sound conservation and management decisions. A basic tenet of science is that research findings can be validated. Natural history collections allow anyone to go back and test the criteria by which a given taxonomic group was established. Without such reference materials we would have no common scientific ground on which to stand, and these debates would go unresolved.

\section{New Approaches}

The utility of scientific museum collections extends far beyond classifying the relationships among plants and animals or delineating the distributions of particular species. Natural history collections are continually being used for ground-breaking research in numerous disciplines. Museum specimens are used to compare present and past conditions in plants and animals for such phenomena as changes in climate, shifts in distribution, occurrence or prevalence of disease, exposure to toxins and contaminants, and changes in population size. 
For example:

- By examining the size, shape, or distribution of individuals, scientists can investigate how specific populations might respond to global warming.

- By deriving the chemical "signatures" of archived museum specimens, it is now possible to infer the migratory origins of individuals or to evaluate their past exposure to environmental contaminants.

- By analyzing the frozen tissues of museum specimens, scientists can test for the historical presence of harmful pathogens and emerging infectious diseases.

- By extracting DNA from archived museum tissues, scientists can investigate changes in population structure or document loss in genetic diversity that accompanies severe range contraction or severe population declines.

Furthermore, the range of uses for museum collections is always expanding. Materials housed in museums are regularly put to use in new and innovative ways to address contemporary questions pertaining to conservation and management. Like the scientists who originally collected each individual specimen, we cannot foresee the true potential of natural history collections. We can, however, anticipate an ever-increasing need. In view of both the current significance of natural history collections and their tremendous potential for fueling future discovery, the USGS participates in ensuring the growth and preservation of these national treasures of fundamental scientific importance.

\section{Research Using the USGS-FORT Collection}

Natural history collections maintained by USGS-FORT at the Museum of Southwestern Biology, University of New Mexico, are regularly put to use both by USGS biologists and the international scientific community. Examples of ongoing studies include:

- inventorying and monitoring vertebrates on national parks and other Federal lands throughout the Western and Central United States;

- investigating the taxonomic relationships and geographic distributions of species of federal concern;

- using specimen occurrence records and stable isotope analysis to determine continental patterns of migration;

- studying the past and current dynamics of infectious diseases (for example, hantavirus) in small mammals; and

- comparing the past and present diets of animals from preserved and newly acquired specimens.

\section{About the USGS-FORT Collection}

The USGS-FORT natural history collection is curated by USGS staff and housed through a cooperative partnership at the Museum of Southwestern Biology, University of New Mexico. The U.S. Fish and Wildlife Service laboratory in Denver, Colorado, started the collection as an adjunct to studies of food habits of carnivores. The collection dates from the late 1920s and early 1930s and now contains specimens collected from across the Rocky Mountains and Intermountain West. Most recently,

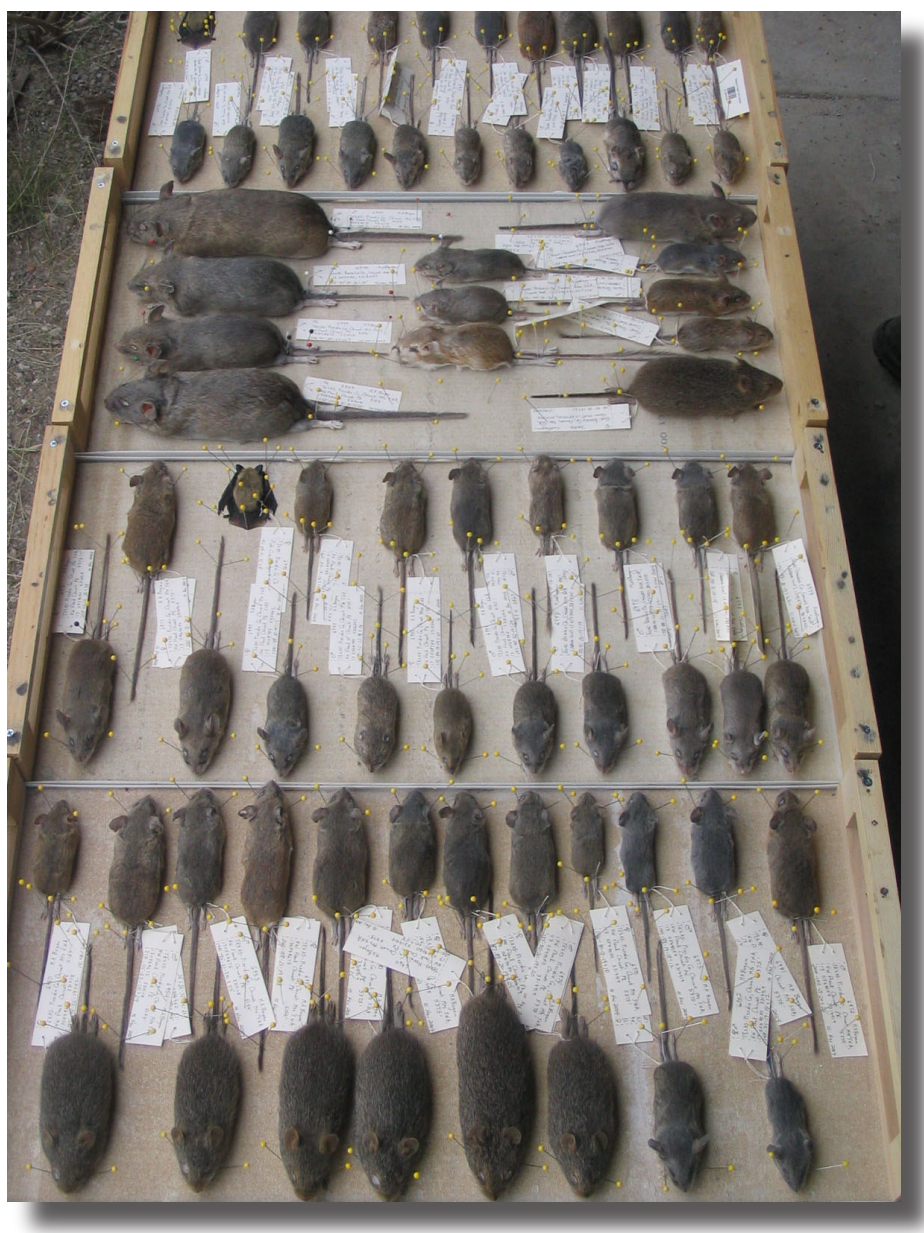

Voucher rodent specimens collected during biological inventories conducted on public lands in Texas. USGS photo.

collection activities have focused on documenting mammal species from public lands in the West, leading to a particularly rich collection of bats and other small mammals. Other specimens in the collection include birds, amphibians and reptiles, and fishes. Of particular relevance are the almost 500,000 fish specimens collected from the Upper Colorado River Basin during or shortly after the closing of the major impoundments in the basin. Some of these fishes are now classified as endangered or threatened under the Endangered Species Act.

For inquiries about curatorial capabilities, research, service or partnership opportunities, please contact:

Cindy Ramotnik, Museum Specialist (Zoology) U.S. Geological Survey, Fort Collins Science Center Department of Biology, University of New Mexico

Albuquerque, NM 87131

Tel: 505-277-5369 Fax: 505-277-0304

E:mail: ramotnik@usgs.gov

\section{Museum of Southwestern Biology, USGS Vertebrate Collection}

http://www.msb.unm.edu/USGS/index.html 